\title{
ASSOCIATIONS BETWEEN MAJOR INDICES OF PHYSICAL DEVELOPMENT AND FITNESS AND THE LEVEL OF ELITE WRESTLER SPECIAL WORK CAPACITY
}

\author{
Oleksandr Pryimakov, ${ }^{1, A, B, C, D}$ Larisa Masenko, ${ }^{2, B, D, E}$ Dmitry Lachno $2, \mathrm{~A}, \mathrm{C}, \mathrm{E}$ \\ ${ }^{1}$ Faculty of Physical Culture and Health Promotion, University of Szczecin, Poland \\ ${ }^{2}$ National Pedagogical Dragomanov University, Ukraine \\ A Study Design; ${ }^{\text {B }}$ Data Collection; ${ }^{\mathrm{C}}$ Statistical Analysis; ${ }^{\mathrm{D}}$ Manuscript Preparation; ${ }^{\mathrm{E}}$ Funds Collection \\ Address for corpespondence: \\ Oleksandr Pryimakov \\ University of Szczecin, Faculty of Physical Culture and Health Promotion \\ Al. Piastów 40b, building 6, 71-065 Szczecin, Poland \\ E-mail: aprim@bk.ru
}

\begin{abstract}
Ahstract. Objective: The objective of the given work consisted in studying associations between the major indices of physical development (PD) and physical fitness, on the one hand, and the level of special work capacity of elite wrestlers of different weight categories, on the other hand. Material: 147 Ukrainian athletes engaged in Greco-Roman, free-style wrestling and judo served as the subjects. The following methods of studies were used: anthropometry, caliperometry, dynamometry, methods of testing speed-strength fitness and special work capacity of wrestlers, statistical processing and computer modelling. Results: It has been demonstrated that skill level determines ratio and associations of morphometric and speed-strength indices, level of athletes' special work capacity. Enhancement of skill level results in augmentation of speed-strength fitness, increase of body circumferences, decrease of fat component content, gain of muscular component and muscular development index. Along with the increase of weight category the level of speed-strength fitness and special work capacity decreases. Respective mathematical models were developed. Conclusions. It is recommended to use the developed regression models for modelling, predicting and evaluating special work capacity of highly skilled wrestlers of light, middle and heavy weight categories.
\end{abstract}

Key world: : wrestlers, skill level, weight categories, associations, physical fitness, models

\section{Introduction}

Physical development and physical fitness are the most important constituents of fitness structure of elite wrestlers (Karelin 2002; Boyko and Danko 2004; Kolenkov et al. 2012; Jushkov and Savchuk 1985; Zaccagni 2012). Along with functional, mental and technical fitness they provide the achievement of the high level of special work capacity and sports result (Jaric 2003; Jagello et al. 2004; Zen-Pin and Ryder 2004; Pryimakov and Kolenkov 2006; Blais et al. 2007).

Carried out analytical studies have allowed to accumulate enormous experimental material about the level of development of individual motor capacities, morphofunctional organization and special work capacity of wrestlers 
(Novikov 1987; Boyko and Danko 2004; Schmidt et al. 2005; Blais et al. 2007; Vardar et al. 2007; Martínez-Abellán et al. 2010). However, these works have failed to sufficiently reflect the fitness structure (FS) of athletes from systemoriented positions, i.e., the positions of ratio and interaction of its components in the process of providing special physical work capacity (Jagello et al. 2004; Pryimakov et al. 2006; Vardar et al. 2007) and sports results (Koshelev 1996; A. Pryimakov et al. 2006) of wrestlers of different weight categories, skill level, sex, etc. Until now, there is no scientifically substantiated approach to differentiated selection of means and methods for improvement of FS of athletes, depending on the level of morphometric development, the degree of development of motor capacities (MC) and motor skills in wrestlers of different weight categories (Pryimakov 2014), skill level (Pryimakov 2013), sex (Kolenkov et al. 2012), etc. Respective criteria have not been substantiated, and the place of physical fitness (PF) in general FS of athletes of different weight categories, sex, skill level, etc., has not been determined. The necessity of system-oriented approach in the capacity of methodological basis for conducting complex studies of PF structure of athletes specialized in combat sports has been mentioned only in few works (Kolenkov et al. 2012; Pryimakov 2014).

Insufficient covering of the majority of these issues in the literature along with their significance for the theory and practice of wrestling have served as the basis for selection of the direction and the subject of study.

The objective of the given work consisted in studying associations between the major indices of the structure of physical development (PD) and physical fitness, on the one hand, and the level of special work capacity of elite wrestlers of different weight categories, on the other hand.

\section{Methods of studies}

The following methods of studies were used: anthropometry, caliperometry, dynamometry, methods of testing speed-strength fitness and special work capacity of wrestlers of different weight categories and skill levels, statistical processing and computer modelling with Statistica application program package (Borovikov 2006), etc.

Indices of height, body mass, body circumference, volume of muscular, bony and adipose tissues, etc. were utilized for evaluation of athletes' PD (Kolenkov et al. 2012). The level of wrestlers' PF was evaluated on the basis of recorded speed-strength indices. Test of throwing the partner of equal weight (one arm forward bending throw) in 3 or 5 sets allowed to evaluate special work capacity. In each set time of performance of 15 throws at maximum rate with 1-min interval of passive rest between the sets was recorded (Novikov 1987; Pryimakov et al. 2006; Kolenkov et al. 2012). Coefficient of wrestlers' special work capacity was calculated (Kolenkov et al. 2012).

For the purpose of comparative evaluation of wrestlers' PD structure, who differed in skill level, all subjects were divided into two groups (1st group - candidates master of sports/CMS/); 2nd group - masters of sports /MS/, international masters of sports /IMS/ and merited masters of sports /MMS/) in one instance, and into 3 groups (1st CMS; 2nd - MS; 3rd - IMS and MMS) - in another.

Members of the national teams of Ukraine in different wrestling styles (free-style, Greco-Roman, judo) of different ages (from 20 to 32 years), skill levels and weight categories served as the subjects. From 14 to 110 athletes participated in different studies.

\section{Resullts of studies}

PD indices of wrestlers, presented in Table 1, demonstrate the increase of neck, chest and tensed shoulder circumferences, index of muscular development, the reduction of fat component percentage as well as the tendency to decrease of bony and increase of muscular components of body surface along with the enhancement of athletes' skill level. 
Tahle 1. Individual indices of physical development of wrestlers of relatively low (CMS) and high (MS, IMS, MMS) skill level

\begin{tabular}{|c|c|c|c|c|c|c|c|c|}
\hline & \multirow{2}{*}{ Indices } & \multicolumn{3}{|c|}{ CMS } & \multicolumn{3}{|c|}{ MS, IMS, MMS } & \multirow{2}{*}{$P$} \\
\hline & & $\bar{x}$ & $\mathrm{~m}$ & $\mathrm{n}$ & $\bar{x}$ & $\mathrm{~m}$ & $n$ & \\
\hline \multicolumn{2}{|l|}{ Weight (kg) } & 71.4 & 1.80 & 32 & 72.7 & 1.72 & 27 & $>0.05$ \\
\hline \multicolumn{2}{|c|}{ Height $(\mathrm{cm})$} & 169.5 & 0.82 & 32 & 169.1 & 1.37 & 27 & $>0.05$ \\
\hline \multicolumn{2}{|c|}{ Mass-height index (g/cm) } & 390.3 & 7.50 & 32 & 427.3 & 7.88 & 27 & $<0.01$ \\
\hline \multicolumn{2}{|c|}{ Index of muscular development } & 6.8 & 0.68 & 32 & 9.2 & 0.76 & 27 & $<0.05$ \\
\hline \multirow{6}{*}{ Circumference $(\mathrm{cm})$} & neck & 38.2 & 0.24 & 32 & 39.4 & 0.44 & 14 & $<0.05$ \\
\hline & chest in rest & 94.1 & 0.94 & 32 & 98.5 & 1.37 & 19 & $<0.05$ \\
\hline & chest during inspiration & 96.0 & 0.96 & 32 & 101.2 & 1.52 & 19 & $<0.01$ \\
\hline & chest excursion & 4.4 & 0.24 & 32 & 5.8 & 0.62 & 19 & $<0.05$ \\
\hline & tensed shoulder & 32.45 & 0.48 & 32 & 34.5 & 0.50 & 27 & $<0.01$ \\
\hline & thigh & 54.2 & 0.61 & 32 & 59.1 & 1.50 & 27 & $<0.01$ \\
\hline \multirow{3}{*}{ Body composition (\%) } & Muscular component & 50.0 & 0.53 & 32 & 51.3 & 0.75 & 14 & $>0.05$ \\
\hline & Fat component & 17.2 & 0.74 & 32 & 13.8 & 0.50 & 14 & $<0.001$ \\
\hline & Bony component & 17.4 & 0.26 & 32 & 16.7 & 0.37 & 14 & $>0.05$ \\
\hline \multicolumn{2}{|l|}{ Body surface $\left(\mathrm{m}^{2}\right)$} & 1.76 & 0.02 & 32 & 1.83 & 0.05 & 14 & $>0.05$ \\
\hline
\end{tabular}

Along with the increase of skill level specific character of adaptation changes in morphological component of wrestlers' FS is also manifested in negative correlations between fat and muscular component $(r=-0.565$, $p=0.0008)$ and between fat and bony component $(r=-0.469, p=0.007)$, and in positive correlations between bony and muscular component $(r=0.421, p=0.01)$ and between bony component and index of muscular development $(r=0.514, p=0.003)$. These associations reflect one of the mechanisms of alteration of body composition component proportions with the increase of athletes' skill level: decrease of fat and increase of muscular components with insignificant changes in bony component.

Linear mathematical models reflecting the strongest dependences of the main morphometric parameters of PD on wrestlers' skill level are presented in Table 2.

Tahle 2. Mathematical models of major PD parameter dependence on wrestlers' skill level (x)

\begin{tabular}{llc}
\hline & Indices & Regression equations $(\mathrm{y})$ \\
\hline & neck & $35.29+2.404 \mathrm{x}$ \\
& lower forearm & $5.166+0.241 \mathrm{x}$ \\
Circumferences $(\mathrm{cm})$ & lower thigh & $8.681+0.632 \mathrm{x}$ \\
& chest & $87.06+5.32 \mathrm{x}$ \\
& tensed shoulder & $30.21+1.56 \mathrm{x}$ \\
\hline Mass-height index $(\mathrm{g} / \mathrm{cm})$ & & $337.5+42.37 \mathrm{x}$ \\
\hline
\end{tabular}

Correlation analysis has demonstrated that skill level of athletes is most closely associated with circumference of the neck $(r=0.660, P<0.01)$, the chest $(r=0.700, p<0.01)$, relaxed $(r=0.630, p<0.01)$ and tensed $(r=0.565$, $p<0.01)$ shoulder. 
Regression models, presented in Table 3, reflect different impact of various combinations of major PD indices of elite wrestlers (circumference of neck, head, chest, shoulder, forearm, thigh, index of muscular development, subcutaneous skinfolds) upon the level of special work capacity.

Table 3. Mathematical models of special work capacity level dependence on major morphometric indices of wrestlers' FS

\begin{tabular}{ll}
\hline \multicolumn{1}{c}{ Regression equations $^{*}$} & $r . p$ \\
\hline$Y_{1}=302.05+6.012 x_{1}-3.77 x_{2}-4.15 x_{3} \pm 11.7$ & $r=0.727, p<0.01$ \\
$Y_{2}=91.372+1.358 x_{1}-1.372 x_{2} \pm 2.69$ & $r=0.831, p<0.01$ \\
$Y_{2}=63.684+2.52 x_{4}-0.983 x_{2}-0.0987 x_{5} \pm 3.45$ & $r=0.715, p<0.01$ \\
$Y_{1}=249.2+4.58 x_{1}-4.09 x_{2} \pm 12.7$ & $r=0.650, p<0.01$ \\
$Y_{1}=213.4+78.5 x_{6}+3.3 x_{1}+1.12 x_{7}+122.4 x_{8}+19.5 x_{9}-5.96 x_{3}-3.45 x_{2}-76.3 x_{10} \pm 42.5$ & $r=0.976, p<0.01$ \\
$Y_{1}=4.9+0.35 x_{4}+0.04 x_{11}-0.029 x_{12}-0.021 x_{5}-0.097 x_{3}-0.07 x_{2} \pm 0.19$ & $r=0.919, p<0.01$ \\
\hline
\end{tabular}

* Notes: $Y_{1}$ - total time of executing throws in three series, 15 in each (sec); $Y_{2}$ - time of execution 15 throws in the first series (sec.); $x_{1}$-thigh circumference $(\mathrm{cm}) ; \mathrm{x}_{2}$ - chest circumference at rest $(\mathrm{cm}) ; \mathrm{x}_{3}$ - neck circumference $(\mathrm{cm}) ; \mathrm{x}_{4}$ - forearm circumference $(\mathrm{cm}) ; \mathrm{x}_{5}$ - head circumference $(\mathrm{cm}) ; \mathrm{x}_{6}$ - relaxed shoulder circumference $(\mathrm{cm}) ; \mathrm{x}_{7}$ - subcutaneous skinfolds under scapula $(\mathrm{mm}) ; \mathrm{x}_{8}$ - body surface $\left(\mathrm{m}^{2}\right) ; \mathrm{x}_{9}$ - index of muscular development; $\mathrm{x}_{10}$ - tensed shoulder circumference $(\mathrm{cm}) ; x_{11}$ - subcutaneous skinfolds of thigh $(\mathrm{mm}) ; x_{12}$ - subcutaneous skinfolds of chin $(\mathrm{m}) ; r$ - correlation coefficient.

Modelling by means of developed regression equations permits to predict orientation of wrestlers' FS perfection according to different combinations of major indices of their PD in the course of controlled long-term adaptation process. In addition, the highest prediction accuracy is achieved when the 5th and the 6th models are used, determination coefficients of which are equal to $95.2 \%$ and $84.4 \%$, respectively.

Analysis of physical fitness indices (Table 4) indicates that highly skilled wrestlers have advantage over relatively low-skill athletes in the level of special work capacity and most of strength and speed-strength indices.

Tahle 4. Speed-strength fitness indices of wrestlers of high (MS, IMS, MMS) and relatively low (CMS) skill level

\begin{tabular}{|c|c|c|c|c|c|c|c|c|c|c|}
\hline & \multirow[t]{2}{*}{ Indices } & \multicolumn{3}{|c|}{ MMS, IMS, MS (1) } & \multicolumn{3}{|c|}{ CMS (2) } & \multirow{2}{*}{$\begin{array}{c}\text { Differences } \\
\% \\
\end{array}$} & \multicolumn{2}{|c|}{$\begin{array}{c}\text { t-Student's, } \\
\mathrm{p}\end{array}$} \\
\hline & & $\bar{x}$ & $\pm m$ & $\mathrm{n}$ & $\bar{x}$ & $\pm m$ & $n$ & & $t_{1-2}$ & $p$ \\
\hline Age, years & & 23.1 & 0.36 & 110 & 19.0 & 0.35 & 36 & 21.6 & 8.15 & $<0.01$ \\
\hline Weight, kg & & 78.4 & 1.75 & 110 & 76.1 & 2.78 & 36 & 3.0 & 0.70 & $>0.05$ \\
\hline \multirow{8}{*}{$\begin{array}{l}\text { Strength and speed- } \\
\text { strength indices }\end{array}$} & $30 \mathrm{~m}$ running (sec) & 4.33 & 0.02 & 106 & 4.44 & 0.03 & 36 & 2.5 & 2.62 & $<0.01$ \\
\hline & Long jump (cm) & 249.6 & 2.87 & 42 & 236.1 & 4.03 & 20 & 5.7 & 2.73 & $<0.01$ \\
\hline & $4 \mathrm{~m}$ rope climbing (sec) & 6.04 & 0.17 & 101 & 6.84 & 0.34 & 36 & 11.07 & 2.11 & $<0.05$ \\
\hline & Pull-ups in $10 \mathrm{sec}$ (number) & 9.9 & 0.12 & 103 & 9.0 & 0.31 & 36 & 10. 0 & 2.63 & $<0.01$ \\
\hline & Push-ups in $10 \mathrm{sec}$ (number) & 19.4 & 0.23 & 87 & 18.0 & 0.69 & 29 & 7.8 & 1.92 & $>0.05$ \\
\hline & Squats with a partner (number) & 23.4 & 0.88 & 100 & 20.9 & 1.92 & 36 & 12.0 & 1.20 & $>0.05$ \\
\hline & Pull-ups (number) & 35.4 & 0.88 & 103 & 30.5 & 2.31 & 36 & 16.1 & 1.96 & $<0.05$ \\
\hline & Push-ups (number) & 72.8 & 1.74 & 103 & 60.6 & 3.16 & 36 & 20.1 & 3.39 & $<0.01$ \\
\hline \multirow{3}{*}{ Special work capacity } & Time of performing 45 throws (sec) & 88.2 & 1.70 & 105 & 109.1 & 3.56 & 36 & 19.2 & 5.30 & $<0.01$ \\
\hline & Work capacity coefficient & 1.061 & 0.004 & 105 & 1.058 & 0.01 & 35 & -0.3 & 0.32 & $>0.05$ \\
\hline & Time of performing 1 throw (sec) & 1.96 & 0.04 & 105 & 2.39 & 0.09 & 36 & 18.0 & 5.29 & $<0.01$ \\
\hline
\end{tabular}


The most apparent advantage of highly skilled athletes is observed in special work capacity test and indices of strength endurance.

Data, presented in Table 5, show that improvement of wrestlers' motor function along with the increase of their expertise is characterized by enhanced speed and intensity of performing throws.

Table 5. Time of specialized motion performance and the degree of work capacity decrease of different skill level wrestlers during throwing test (5 series)

\begin{tabular}{|c|c|c|c|c|c|c|c|c|c|}
\hline \multirow{2}{*}{\multicolumn{2}{|c|}{ Skill level }} & \multicolumn{6}{|c|}{ Series of throws } & \multirow{2}{*}{$\begin{array}{l}\text { Work capacity } \\
\text { decrease (\%) }\end{array}$} & \multirow{2}{*}{$\begin{array}{c}\text { Time of performing } \\
\text { one throw }\end{array}$} \\
\hline & & 1 & 2 & 3 & 4 & 5 & $\Sigma_{1-5}$ & & \\
\hline \multirow{3}{*}{$\begin{array}{l}\text { MMS, } \\
\text { IMS }\end{array}$} & $\bar{x}$ & 25.0 & 25.0 & 25.28 & 24.97 & 25.61 & 125.75 & 6.95 & 1.68 \\
\hline & $\pm m$ & 0.60 & 0.75 & 0.93 & 0.82 & 0.83 & 3.78 & 0.45 & 0.05 \\
\hline & $\mathrm{n}$ & 36 & 36 & 36 & 36 & 36 & 36 & 36 & 36 \\
\hline \multirow{3}{*}{ MS } & $\bar{x}$ & 31.29 & 31.26 & 31.32 & 32.36 & 33.32 & 157.47 & 8.17 & 2.13 \\
\hline & $\pm m$ & 0.61 & 0.75 & 0.85 & 0.77 & 0.75 & 4.14 & 0.63 & 0.05 \\
\hline & $\mathrm{n}$ & 76 & 76 & 76 & 76 & 76 & 77 & 76 & 76 \\
\hline \multirow{3}{*}{ CMS } & $\bar{x}$ & 34.69 & 34.80 & 37.89 & 38.14 & 39.26 & 184.29 & 8.49 & 2.46 \\
\hline & $\pm m$ & 1.16 & 1.33 & 1.62 & 1.43 & 1.39 & 6.78 & 0.54 & 0.09 \\
\hline & $\mathrm{n}$ & 35 & 35 & 35 & 35 & 35 & 35 & 35 & 35 \\
\hline
\end{tabular}

The group of the most skilled athletes (MMS and IMS) differs in more stable work capacity in the dynamics of testing: they have the least percent of work capacity decrease by the 5th series of throws $-6.95 \pm 0.45 \%$ (Table 3 ).

Regression and factor analysis has shown that the major factors of PF structure in groups of relatively low (CMS) and high (MS, IMS, MMS) skill level are those of special work capacity (42.2\% and $31.4 \%$ of total dispersion variations, respectively) and speed-strength endurance (18.8\% and $18.1 \%)$.

Improvement of athletes' skill level is accompanied with the decrease in number of major PF parameters, determining enhancement of wrestlers' special work capacity, increase of the level of their development and the number of high associations between them.

High linear dependence is manifested between the level of special work capacity and skill level of wrestlers $(r=-0.740, p=0.00001)$. For instance, performance of 45 throws during specialized test has been accompanied with significant reduction of total testing time along with the increase of wrestlers' skill level - from $107.4 \pm 3.99 \mathrm{sec}$ in CMS to $93.9 \pm 2.13 \mathrm{sec}-$ in MS, and from $74.5 \pm 2.2 \mathrm{sec}$ in MS to $71.4 \pm 4.0 \mathrm{sec}-$ in MMS.

Below presented model indicates that $54.8 \%$ of the result in special work capacity test is determined by wrestlers' skill level: $y=132.2-18.04 x \pm 14.1$, where $y$ - time of performing 45 throws in sec; $x$ - skill level of athletes in c.u. $(F=52.2, p=0.00001)$.

Method of stepwise regression has allowed to develop the model, reflecting dependence of the result in special work capacity test (while performing 3 series of throws) upon the major speed-strength indices:

$$
y=87.2+0.31 x_{1}+0.564 x_{2}+0.32 x_{3}+2.66 x_{4}-0.186 x_{5}-4.62 x_{6} \pm 12.6
$$

where $y$ - total time of performing 45 throws in 3 series (sec); $x_{1}$ - speed of rope climbing (sec); $x_{2}$ - number of squats with a partner; $x_{3}$ - weight of athlete $(\mathrm{kg}) ; x_{4}$ - number of pull-ups; $x_{5}$ - number of push-ups; $x_{6}-$ speed of push-ups (number performed in $10 \mathrm{sec}$ ). 
Modelling by means of this equation has demonstrated that the most informative speed-strength and strength indices, reflecting the level of wrestlers' special work capacity, are the number of push-ups performed within a definite time interval, the speed of rope climbing and the number of squats with a partner.

Figure 1 illustrates the dynamics of averaged values of time of executing 45 throws in the course of increase of weight categories as well as linear and polynomial graphic models of this dynamics (Figure 1).

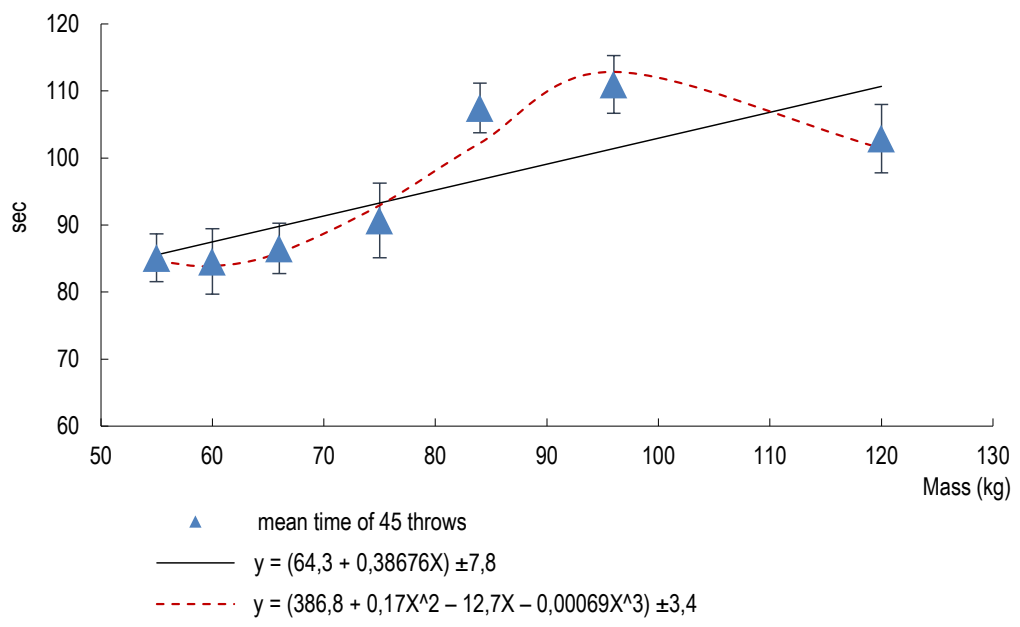

Figure 1. Indices of total time $(y, c)$, expended for execution of 45 one arm forward bending throws by wrestlers of different weight categories $(\mathrm{x}, \mathrm{kg}) . \Delta$ empirical mean group data; linear regression; ------ polynomial regression

Polynomial model most accurately approximates the dynamics of wrestlers' special work capacity during increase of weight category $\left(r^{2}=0.954, p<0.001\right)$.

Non-linear dynamics of work capacity, significant differences between athletes of light, middle and heavy weight categories served as the basis for differentiated elaboration of model characteristics of wrestlers' work capacity, that is, in each of three weight groups of athletes $(55-60 \mathrm{~kg}, 66-74 \mathrm{~kg},>84 \mathrm{~kg})$.

Table $\boldsymbol{b}$. Standard scales for estimating special work capacity of elite wrestlers of 3 groups of weight categories

\begin{tabular}{lcccccc}
\hline & Categories $(\mathrm{kg})$ & \multicolumn{4}{c}{ Estimation (point) } \\
\cline { 3 - 7 } & & 5. & 4. & 3. & 2. & 1. \\
\hline \multirow{3}{*}{ Total time of 45 throws $(\mathrm{sec})$} & $55-60$ & $\leq 46.9$ & $47.0 \leq 53.9$ & $54.0 \leq 60.9$ & $61.0 \leq 74.9$ & $75.0 \leq 81.9$ \\
& $66-74$ & $\leq 44.9$ & $45.0 \leq 53.9$ & $54.0 \leq 62.9$ & $63.0 \leq 80.9$ & $81.0 \leq 89.9$ \\
& $>84$ & $\leq 8.9$ & $59.0 \leq 68.4$ & $68.5 \leq 77.8$ & $77.9 \leq 96.8$ & $96.7 \leq 106.2$ \\
\hline \multirow{2}{*}{ Time of one throw (sec) } & $55-60$ & $\leq 1.04$ & $1.05 \leq 1.20$ & $1.21 \leq 1.35$ & $1.36 \leq 1.66$ & $1.67 \leq 1.82$ \\
& $66-74$ & $\leq 1.00$ & $1.01 \leq 1.20$ & $1.21 \leq 1.40$ & $1.41 \leq 1.80$ & $1.81 \leq 2.00$ \\
& $>84$ & $\leq 1.31$ & $1.32 \leq 1.52$ & $1.53 \leq 1.73$ & $1.74 \leq 2.15$ & $2.16 \leq 2.36$ \\
\hline
\end{tabular}


Method of sygmal deviations was used for elaboration of criteria for estimating special work capacity of elite wrestlers of three groups of weight categories during performance of 45 throws (Table 6).

Presented differentiated scales may be used for estimating the level of wrestlers' special work capacity in points according to time of execution of 45 throws.

\section{Discussion}

Conducted studies demonstrate that skill level and weight category of wrestlers are the most important system-forming factors, determining the level of development, ratio and associations of morphological and speedstrength components of athletes' fitness structure for provision of the high level of special work capacity. Special work capacity and speed-strength endurance are the major components of PF structure of wrestlers.

One of the most important criteria for improvement of general structure of wrestlers' PF is the increase of specific role and associations of relatively small number of the major morphometric and functional parameters, determining the level of special work capacity of highly skilled athletes.

Improvement of PF structure in the dynamics of wrestler skill level enhancement is accompanied with: increase of neck, chest, tensed and relaxed shoulder, and thigh circumferences; reduction of adipose component percentage; tendency to decrease of bony component; increase of body surface and muscular component, augmentation of muscular development index.

Different level of special work capacity of wrestlers of light, middle and heavy weight categories is indicative of the necessity of differentiated approach to its estimation in athletes with different body mass.

Modelling by means of developed equations permits to predict special work capacity level in highly skilled wrestlers at different variants of ratio and associations of the major parameters of physical development and physical fitness.

Elaborated models may be also used for constructing differentiated estimation scales according to complex of the major morphometric and functional parameters as well as for revealing potential optimum combinations of the major indices of PD and PF in order to provide high physical work capacity in the course of controlled long-term adaptation process.

\section{Conclusion}

Special work capacity of highly skilled wrestlers of three groups of weight categories (light, middle and heavy) may be evaluated by means of developed differentiated standard scales according to both total time of performing 45 one arm forward bending throws and time of one throw execution.

Prospects for further development of chosen direction consists in extension of studies focused on examination of ratios and associations of PF structure components, elaboration of respective criteria, standard scales and prognostic models of special work capacity level for each group of athletes, on a case by case basis according to individual weight categories, sex and age, which is quite important for more accurate management of the process of preparation, control and selection of athletes. 


\section{References}

Blais L., Trilles F., Lacouture P. Validation of a specific machine to the strength training of judokas. Journal of Strength \& Conditioning Research. 2007; 21: 409-412.

Bojko V.F., Dan'ko G.V. Physical training fighters, Kiev, Olympic Literature. 2004: 225.

Borovikov V.P., Ivchenko G.I. Forecasting in the STATISTICA for Windows, Moscow, Finance and Statistics. 2006: 275

Danko G.V. The influence of separate training loads on the condition of special efficiency of wrestlers. Physical Education of the Student of Creative Specialties. Kharkov. 2004; 5: 9.

Jagello V., Tkachuk V., Blakh V. Correlation of anthropometric parameters with a level of sporting skill of the highly qualified judoists of Poland. Physical Education of the Students of Creative Profession. 2004; 2: 36.

Jaric S. Role of body size in the relation between muscle strength and movement performance. Exercise and Sport Sciences Reviews. 2003; 31 (1): 8-12.

Jushkov O.P., Savchuk A.N. Study of the interrelationship of technical skill level of the physical qualities of young fighters. Theory and practice of physical culture. 1985; 8: 23-24.

Karelin A.A. Sports training fighters qualifications. Novosibirsk. 2002: 479.

Kolenkov O.V., Pryimakov O.O., Pristins'kij V.M., Osipcov A.V. Modeling the structure of the special physical fitness skilled fighters on the stage of maximum realization of individual features. Donetsk. Noulidzh. 2012: 165.

Koshelev V.E. System-analytical approach to the problem of control of trained athletes. Theory and practice of physical culture. 1996: 10: $55-58$.

Martínez-Abellán A García-Pallarés. J., López-Gullón J., Muriel X., Morales V., Martínez-Moreno A. Factores Anaeróbicos Predictores del Éxito en Lucha Olímpica. Cuadernos de Psicología del Deporte. 2010; 11: 17-23.

Novikov S.P. Pedagogical Tests and criteria for evaluation of performance of the current heavyweight judokas. Theory and practice of physical culture. 1987; 6: 39-40.

Pryimakov A.A., Kolenkov A.V. Model features of dependence of a level of special efficiency with qualification and weight category of wrestlers .Physical Education of the Students of Creative Profession. 2006; 5: 51-60.

Pryimakov A.A., Kolenkov A.V., Machaidze E.P. Morpho-functional interconnection and speed-strength performance structure of physical fitness skilled fighters. Pedagogics, psychology, medical-biological problems of physical training and sports. Kharkov. 2006; 2: 99-103.

Pryimakov A.A. Model characteristics of the structure of the special physical preparedness fighters qualifications. Pedagogics, psychology, medical-biological problems of physical training and sports. Kharkov. 2013; 6: 96-102.

Pryimakov A.A. Comparative characteristics structure physically prepared fighters high qualification light, medium and heavy weight category. Pedagogics, psychology, medical-biological problems of physical training and sports. Kharkov. 2014; 9: 47-53.

Schmidt W.D., Piencikowski C.L., Vandervest R.E. Effects of competitive wrestling season on body composition, strength, and power in national collegiate athletic association division III college wrestlers. Journal of Strength and Conditioning Research. 2005; 19: 505-508.

Vardar S.A., Tezel S., Ozturk L., Kaya O. The relationship between body composition and anaerobic performance of elite young wrestlers. Journal of Sports Science and Medicine. 2007; 6: 34-38.

Zaccagni L. Anthropometric characteristics and body composition of Italian national wrestlers. European Journal of Sport Science. 2012; 12 (2): 145-151. DOI: 10.1080/17461391.2010.545838.

Zen-Pin L., Ryder C.E. The study of physiological factors and performance in welterweight taekwondo athletes. Sport Journal. 2004; 7 (2): $34-40$.

Cite this article aS: Pryimakov O., Masenko L.,Lachno D. Associations between Major Indices of Physical Development and Fitness and the Level of Elite Wrestler Special Work Capacity. Central European Journal of Sport Sciences and Medicine. 2015 ; 11 (3): 87-94. 